\title{
Pesquisa e leitura em foco: uma proposta de multiletramentos voltada para o ensino de ortografia
}

\author{
Reading and research in focus: a proposal of multiliteracies dedicated \\ to the teaching of spelling
}

\begin{abstract}
RESUMO: O presente artigo parte de uma pesquisa voltada para a produção de uma proposta de atividade para o ensino de língua portuguesa baseada na Pedagogia dos Multiletramentos, que considera a multiculturalidade da sociedade globalizada e a multimodalidade dos textos que a constituem. A proposta de atividade aqui apresentada sugere que seja feito um trabalho intenso com leitura e pesquisa, utilizando o meio digital como suporte para estudo de questões relacionadas à ortografia. Os alunos serão instigados a realizar uma pesquisa para análise de regras ortográficas e seus usos correntes em perfis de redes sociais. Com este trabalho o professor poderá explorar a diversidade linguística e cultural da sociedade contemporânea, além de possibilitar o contato com vários gêneros textuais. A proposta também aborda o ensino de ortografia por meio do Jogo Soletrando, proporcionando o divertimento e o aprendizado dos alunos de forma lúdica e interessante.
\end{abstract}

PALAVRAS-CHAVE: Ensino de ortografia. Leitura e pesquisa. Jogos.

\section{Thais Nunes Xavier dos SANTOS*}

\begin{abstract}
This article is based on a research focused on the production of a proposal for a Portuguese language teaching activity based on Pedagogy of Multiletraces, which considers the multiculturality of globalized society and the multimodality of the texts that

constitute it. The activity proposal presented here suggests that an intense work be done with reading and research, using the digital medium as a support to study questions

related to spelling. Students will be encouraged to conduct research to analyze orthographic rules and their current uses in social networking profiles. With this work

the teacher will be able to explore the linguistic and cultural diversity of the contemporary society, besides making possible the contact with several textual genres. The proposal also addresses the teaching of spelling through the Spelling Game, providing fun and learning for students in a playful and interesting way.
\end{abstract}

KEYWORDS: Spelling. Reading and research. Games.

\section{INTRODUÇÃO}

O presente artigo é resultado do trabalho desenvolvido no primeiro semestre letivo do ano de 2017, na disciplina de Alfabetização e Letramento, no Programa de Pós-graduação Mestrado Profissional em Letras (ProfLetras), da Universidade Federal de Uberlândia.

Este trabalho versa sobre o ensino de ortografia nas aulas de língua portuguesa, ancorado em uma proposta de multiletramentos. Uma vez observada a crescente dificuldade dos alunos em escrever de acordo com os padrões ortográficos da língua, tornou-se necessária a elaboração de uma proposta de ensino, baseada nos

\footnotetext{
* Professora de Língua Portuguesa da Rede Municipal de Uberlândia. Aluna mestranda do curso de Mestrado Profissional em Letras da Universidade Federal de Uberlândia. tatanx18@ hotmail.com
} 
multiletramentos, que abordasse de forma clara, objetiva e prazerosa, o trabalho com a ortografia. Nossa proposta baseia-se em fundamentos teóricos sustentados pelos autores Rojo e Moura (2012), Dudeney, Hockly e Pegrum (2016), Morais (2010), acerca de estudos sobre letramento, multiletramentos, letramentos digitais e ensino de ortografia.

É recorrente nas produções textuais dos alunos, independentemente do gênero em foco, muitos problemas oriundos de dificuldades ortográficas. As aulas de língua portuguesa, em sua maioria, apresentam aos alunos o sistema ortográfico e de escrita da língua, norteados por regras e normas da gramática normativa, baseadas em situações comunicativas artificiais e descontextualizadas

A exemplo disso, alguns livros didáticos, como os livros da coleção Português linguagens de $6^{\circ}$ ao $9^{\circ}$ ano do Ensino Fundamental, de Willian Roberto Cereja e Thereza Cochar apresentam a seção referente aos aspectos fonéticos e fonológicos da língua relacionados à ortografia muito reduzida.

Partindo do pressuposto de que o livro didático é o grande norteador do trabalho do professor em sala de aula, esse recurso não contempla de forma eficaz o ensino de ortografia da língua portuguesa, já que o grande enfoque do ensino - pautado em um documento de maior instância e abrangência, a saber, os PCN (Parâmetros Curriculares Nacionais) - são os gêneros textuais.

Segundo esse documento, a língua portuguesa deve ser ensinada partindo do texto como objeto de estudo, abordando os gêneros textuais e suas especificidades, como estilo, conteúdo e estrutura composicional. Ou seja, o ponto de vista macrolinguístico está em evidência na maior parte do tempo durante as aulas, enquanto os aspectos microlinguísticos, formais do texto em si, também relevantes, não recebem a atenção necessária para o aprendizado eficaz da língua portuguesa, em seus aspectos ortográficos.

Se o objetivo é que o aluno aprenda a produzir e a interpretar textos, não é possível tomar como unidade básica de ensino nem a letra, nem a sílaba, nem a palavra, nem a frase que, descontextualizadas, pouco têm a ver com a competência discursiva, que é questão central. Dentro desse macro, a unidade básica de ensino só pode ser o texto, mas isso não significa que não se enfoquem palavras ou frases nas situações didáticas específicas que o exijam. (BRASIL, 1997, p.29) 
Infelizmente, o que observamos é uma situação de extremos: ou se trabalha com aspectos gramaticais isolados e descontextualizados, que não configuram significância para o ensino de língua portuguesa, ou o ensino voltado para uma abordagem que leva em consideração aspectos textuais que caracterizam os gêneros, imprescindíveis para o desenvolvimento da competência discursiva.

Percebemos que só um dos aspectos não deve ser o enfoque da proposta de ensino de língua portuguesa. Tanto os aspectos macrolinguísticos quanto os microlinguísticos são essenciais para o desenvolvimento da competência discursiva, principal objetivo do ensino de língua materna.

Consideramos, então, que o ensino de língua portuguesa deve partir do estudo do texto em suas especificidades, para tratar de aspectos gramaticais e ortográficos, também importantes para o estudo da língua. A partir da leitura e do estudo de textos de diferentes tipologias e diversos gêneros, o aluno terá condições de se identificar como um indivíduo conhecedor de sua própria língua, utilizando-a para agir em todas as esferas de sua vida.

Outro aspecto importante é a rotina das atividades escolares que mostra o pouco trabalhado em sala de aula com a oralidade e a ênfase no exercício da escrita. Desde que a escrita foi inventada, a oralidade perdeu seu valor e passou a ser vista como secundária para a sociedade. Esta situação é vivida no ambiente escolar em que não há preocupação em se trabalhar a língua por meio da modalidade falada. Muitos professores apresentam dificuldade em desenvolver atividades que estejam no âmbito dos gêneros orais.

Dada a idealização da escrita como forma perfeita da língua - e, logo, da expressão da realidade e do pensamento - , a fala só pode ser concebida de duas formas, aliás, não mutuamente exclusivas: seja como tendente necessariamente à forma ideal, representada precisamente pela escrita, fundindo oral e escrita numa unidade mítica de uma língua ideal; seja como fundamentalmente diferente da escrita em sua forma e em sua função, já que ela é o lugar da expressão espontânea da cotidiana que, por definição, não tem cidadania no sistema escolar. (SCHNEUWLY, 2004, p.133)

Diante do exposto, pretendemos apresentar aqui uma proposta de multiletramentos para o ensino de ortografia com o objetivo de desenvolver no discente a consciência fonética e fonológica da língua a partir da leitura e do contato com alguns gêneros textuais. Nosso intuito é amenizar dificuldades ortográficas apresentadas pelos alunos de $8^{\circ}$ ano do Ensino Fundamental, ano escolar ao qual se destina esta proposta, 
bem como apresentar uma oportunidade de se trabalhar a oralidade em aula de língua materna. Assim, por meio de atividades interativas que despertam o interesse de muitos alunos, propomos uma análise de regras ortográficas e suas aplicações por intermédio de pesquisas em textos presentes em perfis de redes sociais.

A escola contemporânea conta com a presença de nativos digitais em seu meio, interconectados na maior parte do tempo com inúmeras informações do mundo digital, muitas vezes, desperdiçadas em situações de uso as quais não acrescentam conhecimento à vida do estudante. De fato, a escola não tem outra alternativa a não ser adequar-se às transformações sociais e digitais pelas quais a sociedade vem passando, propondo ao aluno digitalmente letrado outros caminhos para a aprendizagem, mais prazerosos, interessantes e reais.

Almejando os objetivos apresentados, o presente artigo está organizado em três partes. Após a introdução, que se refere à parte 1, discorremos sobre os pressupostos teóricos, referente à parte 2 , os quais fundamentam nossa proposta e que estão divididos em quatro seções, e, finalmente, tecemos as considerações finais, correspondendo à parte 3.

\section{FUNDAMENTAÇÃO TEÓRICA}

\subsection{O ENSINO DE ORTOGRAFIA}

Desde o início da escolarização, o processo de alfabetização é pautado na oralidade e na "fonetização" em que se observam os sons da fala para ensinar a língua escrita. No entanto, o processo de desvencilhar a língua escrita da falada, já que são duas modalidades de representação de uma língua, cada uma com suas especificidades, pode parecer tardio uma vez que é perceptível a grande dificuldade que os alunos têm, mesmo em anos escolares mais avançados, em separar a língua portuguesa falada da língua escrita.

A situação torna-se um problema uma vez que os alunos escrevem como se estivessem falando sobre determinado assunto. Isso pode ser exemplificado quando eles escrevem orientados pelo som das palavras quando são pronunciadas. Há uma grande dificuldade em diferenciarem o som de sua representação gráfica nas palavras com sílabas finalizadas com a consoante "l”, por exemplo, em que eles trocam pela vogal "u”, e vice-versa, como nas palavras "saudável”, quando é escrita da seguinte forma: 
"saudáveu", ou "saldável"; ou ainda, a palavra "sal", aparecendo como "sau", não diferentemente com os vocábulos "auto" e "alto", em que os alunos escrevem "auto" (para se referir à altura e suas derivações) e "alto" (para se referir à automóvel, por exemplo, e suas derivações).

Outro aspecto também é a confusão entre o som da letra "e" e seu grafema, quando os alunos confundem com o som da letra "i”, a título de exemplo, ocorrências em que os alunos escrevem a preposição "de" na forma "di", demonstrando o som que a vogal "e" apresenta na fala, assim como nas palavras "penti", "denti”, "vinti”, quando a forma adequada para a escrita, baseada nas convenções ortográficas da língua, é "pente", "dente", "vinte".

Há diversas outras situações em que os alunos não conseguem representar o fonema e seu respectivo grafema e acabam acrescentando vogais em palavras como "mas". Depois de escrevê-la, ela se torna "mais", e eles não percebem a diferença de sentido entre as palavras "mais e mas". Os verbos que se encontram no infinitivo também sofrem alterações quando representados graficamente pelos alunos com dificuldade, pois escrevem de acordo com a fala, como, por exemplo, em frases "eu vou cantá / quero come macarrão", e não colocam a consoante "r" no final deles.

Muitas vezes, o ensino que se propõe a abordar a ortografia acontece de maneira superficial e não contempla as dúvidas dos alunos quanto a esse assunto amplo e inexato. O que não se compreende em ortografia, na maior parte dos casos, é desconsiderado ou simplesmente deixado para ser trabalhado a posteriori. O fato é que os alunos não veem sentido em estudar regras ortográficas, não compreendem a sua relevância e sua utilização.

O problema torna-se mais evidente quando os alunos se deparam com palavras para as quais não há regras que explicam por quais motivos são escritas de tal maneira. Isso porque eles não têm a noção de que a ortografia é um conjunto de convenções sociais que ditam a forma correta, dentro da norma culta, de se escrever determinada palavra. Quando acontece isso, o aluno deveria ser orientado a refletir sobre a sua língua e memorizar as palavras que lhe são mais comuns ou de uso mais frequente.

É necessário compreender que o ser humano já nasce apto a falar, observando-se suas faculdades mentais, de modo a dominar uma gramática internalizada que o capacita a se comunicar com primazia em sua própria língua. Segundo Marcuschi (2008, p.18) “A fala (enquanto manifestação da prática oral) é adquirida em contextos informais do 
dia-a-dia e nas relações sociais e dialógicas que se instauram desde o momento em que a mãe dá seu primeiro sorriso ao bebê."

Todavia, a modalidade escrita da língua é aprendida, ou seja, o indivíduo não a adquire de forma natural, não lhe é inerente. Uma forma de aprender a língua escrita é através do ingresso à escola. O mesmo acontece com a ortografia, o aluno não a assimila sozinho, trata-se de um processo de aprendizagem que necessita de métodos e estratégias, dentro de um ensino sistemático.

Dada a sua natureza de convenção social, o conhecimento ortográfico é algo que a criança não pode descobrir sozinha, sem ajuda. Quando compreende a escrita alfabética e consegue ler e escrever seus primeiros textos, a criança já aprendeu o funcionamento do sistema de escrita alfabética, mas ainda desconhece a norma ortográfica. (MORAIS, 2010, p. 28)

Dessa forma, considerando o ensino de ortografia importante para a comunicação escrita, nas suas exigências formais, a escola precisa voltar seus olhares para a ortografia em si e incentivar a curiosidade do aluno, quando questiona como se escreve determinada palavra, qual consoante ou vogal ele deve utilizar. Essa curiosidade do aluno caracteriza uma forma de refletir sobre a língua e deve servir de motivação para o trabalho com a ortografia.

\subsection{MULTILETRAMENTOS}

O problema que a educação tem enfrentado no transcorrer dos anos está relacionado ao letramento. Conforme Magda Soares (1999), antes do surgimento do conceito de letramento, na década de 80 , a grande preocupação era o analfabetismo crescente entre as crianças, apontado pelas pesquisas realizadas na época. Porém, com o advento do ensino baseado no letramento e não apenas na alfabetização, o enfoque mudou e as preocupações agora são outras: a de o aluno ser alfabetizado e letrado, ou seja, capaz de realizar diferentes atividades comunicativas em práticas sociais de leitura e escrita.

O desafio dos professores, então, é levar os indivíduos a envolver-se em práticas sociais de leitura e de escrita. É por meio da linguagem que o indivíduo desenvolve sua capacidade crítica para a efetiva participação em uma sociedade realmente democrática, capaz de reconhecer seus direitos e deveres como cidadão. Nesse viés, a escola é vista pela comunidade em geral como uma instituição social própria para o contato entre o 
aluno e as variadas formas de utilização da leitura e da escrita, abordando tanto a cultura escolar quanto a cultura dominante, como também as diferentes culturas locais e populares com as quais a comunidade escolar está envolvida.

Entretanto, o envolvimento durante as atividades, necessário para uma aprendizagem eficaz, não acontece nas aulas de língua portuguesa, ou não o suficiente ou adequado para atingir tais objetivos. Dentre outros fatores, a falta de envolvimento por parte dos alunos e também a preparação por parte dos professores para encaminhálos em tal direção pode ser uma das explicações possíveis para tantos problemas de aprendizagem.

Talvez por isso, pensando em motivos e explicações, os alunos não conseguem aprender, internalizar, apropriar-se da língua portuguesa para comunicar-se, expressarse de maneira eficiente, tão pouco realizar sua trajetória escolar com êxito. É provável que seja aí a origem do repúdio às aulas de língua portuguesa, porque não conseguem ver sentido em estudar regras gramaticais, - em especial, aqui, as regras ortográficas ditadas pela gramática normativa, ou outros conteúdos dentro da disciplina.

Rojo e Moura (2012) afirmam que o ensino baseado em uma pedagogia de multiletramentos fundamenta-se na necessidade de considerar a multiculturalidade da sociedade moderna e globalizada e a multimodalidade dos textos, através dos quais a multiculturalidade se manifesta. Assim, multiletramentos refere-se a "multiplicidade cultural das populações e a multiplicidade semiótica de constituição dos textos por meio dos quais ela se informa e se comunica.” (ROJO; MOURA, 2012, p.13).

Pensar em uma proposta de multiletramentos para o ensino de ortografia implica partir de fatos que transcendam o próprio conhecimento do aluno, considerando o espaço em que vive, a língua que fala, as atividades que realiza, a forma como vê o mundo e se vê no mundo, as relações sociais que permeiam sua vida. Além disso, os alunos estão inseridos em uma sociedade letrada, que se transforma rotineiramente e se comunica por meio de uma infinidade de gêneros discursivos, materializados em textos multimodais, multissemióticos e hipermidiáticos.

Diante do exposto, o ensino de ortografia faz-se necessário para que o aluno possa comunicar-se efetivamente dentro de sua língua, adequando-se aos padrões da língua escrita formal, reconhecendo-a como fundamental para sua trajetória escolar e sua vida social e profissional. Conforme Morais (2010, p. 25) “Assim sem abrir mão da leitura e produção de textos como eixos orientadores do trabalho com a língua, penso que é preciso ensinar ortografia. E fazê-lo de maneira sistemática." 


\subsection{LETRAMENTOS DIGITAIS}

É inegável a significativa evolução das tecnologias digitais no meio social cuja utilização está imbricada em quase todos, senão todos, os segmentos da vida moderna. Obviamente, a escola encontra-se em meio a esse panorama de transformações e avanços e se vê obrigada a adequar-se às exigências da sociedade contemporânea.

Com efeito, o ensino tradicional, fundamentado no letramento impresso, caracteriza-se como obsoleto, privando os alunos do seu contato com o que realmente está a sua volta em um contexto extraescolar. É incoerente manter uma metodologia de ensino a qual não prepara o aluno para o mundo real, vinculado às transformações sociais promovidas pelas ações humanas e avanços tecnológicos.

A escola, constituída em moldes ultrapassados de ensino, os quais não contemplam os avanços tecnológicos que permeiam o meio social, deve repensar seu papel enquanto instituição formadora, com a finalidade de instruir através de valores sociais, virtudes, ética, cidadania para uma sociedade justa e consciente de seus direitos e deveres. A instituição deve desenvolver nos aprendizes, conforme Dudeney; Hocly; Pegrum (2016. p. 17), "habilidades individuais e sociais necessárias para interpretar, administrar, compartilhar e criar sentido eficazmente no âmbito crescente dos canais de comunicação digital."

É passível aos olhos a urgência com que os estudantes clamam pela transformação do ensino em algo mais palpável e contextualizado, condizente com a sua realidade. Essa evolução do ensino, proporcionando a familiarização com as possibilidades de aprendizagem por meio dos letramentos digitais, deve acontecer progressivamente, de modo que os benefícios sejam aproveitados.

Em vista de se envolverem plenamente com as redes sociais, ter acesso a vagas de emprego nas economias pós-industriais de conhecimento e assumir papéis como cidadãos globais confortáveis em lidar com diferenças interculturais, nossos estudantes carecem de um conjunto completo de letramentos digitais a sua disposição. (DUDENEY; HOCLY; PEGRUM. 2016, p. 17)

O ensino baseado nos letramentos digitais pressupõe um trabalho intenso de leitura e escrita, habilidades imprescindíveis para que a comunicação seja estabelecida no meio digital. Nesse sentido, o professor exercerá uma função orientadora e 
mediadora entre os alunos e o conhecimento construído por intermédio dos recursos digitais.

\subsection{UMA PROPOSTA DE MULTILETRAMENTOS VOLTADA PARA O ENSINO DE ORTOGRAFIA}

O ensino de língua portuguesa deve partir do princípio de que a linguagem é a mentora de toda e qualquer situação comunicativa, seja ela verbal ou não verbal. Os gêneros estão presentes na vida da sociedade, comprovando que a linguagem é o meio pelo qual acontece a interação entre os sujeitos com as mais diversas intenções. A língua é um ato social, caracterizada pela interação verbal ou não verbal em que um indivíduo se comunica com outro, atingindo seus objetivos e intenções.

$\mathrm{O}$ ato de escrever, de produzir um texto só é possível porque o ser humano consegue se comunicar através da linguagem numa relação dialógica. Conforme Bakhtin (1929) as relações entre o homem e a linguagem, que permeia toda atividade humana, são baseadas nas relações entre o eu e o outro, numa relação de interação verbal, dialogicamente. O dialogismo observado é o princípio básico da existência humana, já que o eu constitui o outro e é por ele constituído. Assim, todo texto apresenta caráter dialógico, formado por várias vozes.

Desta forma, a produção de texto do aluno tem uma intenção principal de que o outro leia o seu texto. Ou seja, o objetivo de quem escreve um texto é atingir um leitor, para que o outro o leia. Assim, é importante que o aluno desenvolva a consciência de que, ao escrever, o outro terá contato com o que escreveu, com seu texto, suas ideias e seu conhecimento sobre os recursos linguísticos necessários para que o texto faça sentido, numa relação coerente e coesiva.

Uma vez que o texto expressa as mais variadas facetas do autor, é necessário que o indivíduo escreva de maneira que o seu leitor o compreenda. Dessa forma, o ensino da convenção ortográfica é relevante para que o aluno possa expressar-se dentro dos padrões formais da escrita, mediante situações comunicativas as quais lhe exigem um comportamento linguístico mais formal e monitorado.

Por este viés, destinada a alunos de $8^{\circ}$ ano do Ensino Fundamental, os quais podem apresentar em seu histórico escolar uma crescente dificuldade ortográfica, quando analisadas as suas produções textuais, uma proposta de multiletramentos pode ser uma opção eficaz para se ensinar a ortografia, atendo-se a outros aspectos linguísticos e culturais, além de regras ortográficas. 
Incialmente, a proposta parte do estudo do texto como base para um debate temático sobre o intenso uso das redes sociais pelos adolescentes nos dias atuais. Por meio de um Datashow, o professor irá apresentar duas reportagens sobre o uso das redes sociais, com os seguintes títulos: " $90 \%$ dos jovens brasileiros possuem pelo menos um perfil nas redes sociais" (EXAME, 29/07/2015) e "Cresce exposição de jovens na internet" (ESTADÃO, 02/12/2012). As reportagens tratam de assuntos polêmicos envolvendo a grande exposição de adolescentes, em idades ainda prematuras, em redes sociais, analisando dados de pesquisas realizadas com diversos jovens, de faixas etárias diferentes, e servirão de base para as discussões sobre o tema.

Posteriormente, o professor aplicará um questionário, que poderá ser criado pelo próprio docente, como forma de sondagem para que os alunos respondam, através do Google Formulários, sobre o seu contato com as redes sociais, se possuem algum perfil, se acessam com frequência. A partir das respostas dos alunos, o professor poderá criar um gráfico da turma, juntamente com os alunos, referente à intensidade de uso das redes sociais e discuti-lo. Aqui fica clara a intenção da proposta de se trabalhar com o multiletramento, em que o aluno poderá debater e opinar sobre um tema polêmico que permeia nossa sociedade, partindo do que ele já sabe ou pratica.

Mediante conversa com os alunos, o professor poderá elencar assuntos sobre ortografia que a turma tenha mais dificuldade. Ressaltamos aqui a escolha do uso da letra S em diversas palavras cujo som pode ser representado por: S, SS, X, C, Ç, SC. São situações de representações gráficas, de acordo com as convenções da escrita, que os alunos mais apresentam dúvidas quanto à escrita ortográfica adequada.

Após as atividades de leitura e discussão dos textos por meio de um debate sob a orientação do professor, os alunos farão uma análise do texto das reportagens, listando as palavras que apresentam o som da letra S, mas são representadas por outras consoantes, como, por exemplo, as palavras: "exposição, sociais, crianças, crescimento". Os alunos poderão realizar a atividade em duplas, no laboratório de informática, com internet disponível, e com o pacote Office instalado, para que façam a listagem de palavras digitadas no software Word.

Sugerimos, nesse momento, que o professor leve para a turma as regras de uso da letra S para aquelas palavras regulares da língua, as quais são explicadas por meio de regras, e também aborde a questão das irregularidades da língua, para as quais não há regras que explicam a sua ocorrência. Esta atividade deverá ser realizada mediante exemplos de palavras a serem analisadas, sugeridas tanto pelos alunos quanto pelo 
professor. Consideramos que aqui seria uma excelente oportunidade para conversar com os alunos sobre a utilidade das gramáticas, impressas ou online, bem como dos dicionários para eventuais consultas em situações de dúvidas acerca da escrita de alguma palavra.

Na sequência, propomos que os alunos participem de uma atividade mais lúdica, estimada pela maioria, que é um jogo online denominado Soletrando. O jogo é uma forma de complementar a atividade de estudo da ortografia, explorando as competências da leitura, da audição e da escrita, além de ser um divertimento. Para tanto, o professor explicará aos alunos sobre o funcionamento do jogo, informando que é uma atividade baseada no jogo Soletrando, do programa Caldeirão do Huck, da Rede Globo, em que o aluno ouve a palavra em questão, digita-a de acordo com a forma que ouviu, dentro de um tempo cronometrado e confirma se está correta ou não. Se o aluno acertar as palavras soletradas, prossegue no jogo, passando para uma nova fase.

Em outro momento, os alunos farão uma pesquisa em seus perfis em redes sociais, observando as postagens, os comentários, o texto que os usuários escrevem. A partir desta observação, os alunos analisarão as palavras escritas em desacordo com a norma ortográfica e farão o registro no software Word para utilizarem, posteriormente, na finalização do trabalho.

A partir dos registros realizados na atividade anterior, propomos que os alunos, em grupo, analisem as ocorrências encontradas em desacordo com as regras ortográficas estudadas para o uso da consoante $\mathrm{S}$, e formulem possíveis soluções para os problemas de escrita. Nesse momento, sugerimos que o professor aproveite para conversar com os alunos a respeito da preservação da identidade em trabalhos que envolvam a pesquisa de dados com seres humanos. Ele deverá orientá-los quanto ao registro das palavras sem identificar quem cometeu a inadequação ortográfica, porque o que importa para o pesquisador são os dados coletados para a pesquisa.

A sequência didática direciona o trabalho agora para uma preparação da apresentação da pesquisa dos grupos. É relevante informar aos alunos sobre a importância de socializar dados de uma pesquisa realizada e não deixá-los apenas arquivados, assim como é importante transmitir e compartilhar o conhecimento que se tem sobre determinado assunto. Dessa forma, pensamos que o aluno se sentirá motivado a concluir seu trabalho e se interessará pelo universo da pesquisa em si, observando-se sua precisão para a produção de saberes. 
O professor auxiliará os alunos a utilizarem o software PowerPoint, com suas particularidades de uso, para que eles possam organizar os dados de sua pesquisa em uma apresentação no DataShow. Os grupos deverão organizar uma apresentação formal contendo os dados coletados, suas análises e percepções, as possíveis soluções para os problemas encontrados e a conclusão da pesquisa. Consideramos que seja desenvolvido com a turma um trabalho sistemático de como realizar uma apresentação oral, como deve ser o comportamento do grupo que estará apresentando e qual a linguagem mais adequada a ser utilizada neste momento. É importante que o aluno perceba a importância da comunicação oral e que estará sendo avaliado pela forma como se comportar e falar.

Os grupos farão as apresentações na sala de informática, ou onde melhor lhes convier, desde que tenha o aparato tecnológico necessário para o desenvolvimento da atividade. Enquanto os grupos fazem as apresentações, pressupomos que o professor faça anotações necessárias sobre as considerações a respeito dos trabalhos. Para a conclusão da sequência didática, sugerimos que o professor organize um momento para informar suas considerações aos grupos, no intuito de apontar o que foi considerado bom e o que deve ser melhorado nos trabalhos apresentados. O professor deverá levar em consideração aspectos como dados da pesquisa, compreensão da teoria, aparência dos slides, comportamento na apresentação.

Todo o trabalho realizado até aqui servirá de base teórica para o desenvolvimento de uma atividade que será executada entre as turmas de $8^{\circ}$ ano, baseada na competição do jogo Soletrando. O jogo é inspirado no oficial, apresentado no Programa Cadeirão do Huck, em que os alunos participarão de competições entre si de soletração de palavras aleatórias, à escolha do professor.

Os alunos se organizarão em equipes de, no máximo, cinco alunos e o professor passará para cada equipe uma lista de possíveis palavras que poderão ser questionadas no momento da soletração. O professor deverá estabelecer um prazo para o estudo das palavras e organizar um momento da aula para realizar o jogo. Sugerimos que as listas sejam entregues com um prazo de cinco dias para o estudo prévio.

O professor fará a competição na aula elencando os vencedores de cada equipe. A palavra será falada pelo professor, o aluno a ouvirá e terá direito a optar por uma das ajudas seguintes: a definição, a aplicação em uma frase, ou um sinônimo da palavra. Assim que estiver preparado, o aluno falará a palavra, em um tempo máximo de cinco minutos, letra por letra, e depois, a palavra na íntegra. O professor julgará se a 
soletração está correta ou não. O aluno que acertar acumula pontos para a equipe e prossegue no jogo. Se errar, a equipe não pontua e o aluno será eliminado da competição.

Posteriormente, o professor realizará a competição entre os vencedores de cada equipe, elegendo o campeão da sala. $\mathrm{O}$ jogo poderá abranger outros segmentos da escola, como outras séries, outras turmas, e até um campeonato envolvendo a escola inteira, para que seja destacado o campeão da instituição.

\section{CONSIDERAÇÕES FINAIS}

A proposta de multiletramentos voltada para o ensino da ortografia deverá ser finalizada com o jogo Soletrando, o qual poderá ser realizado fora do ambiente da sala de aula, transpondo-se para um local de maior destaque na escola. Isso proporcionará ao aluno a percepção de um mundo de possibilidades que se abre para aqueles que estão dispostos a aprender, a conhecer e a se transformar.

A partir dessa proposta de multiletramentos, o aluno perceberá o ensino fundamentado em aspectos culturais sobre sua realidade, bem como a aplicação de regras ortográficas em contextos mais palpáveis, como a análise de textos em perfis de redes sociais, difíceis de perceber quando o ensino é fundamentado apenas no livro didático, com exemplos clássicos.

A sequência didática propicia ao aluno o contato com vários gêneros e formas de comunicação por meio da linguagem. Dessa forma é possível perceber o verdadeiro sentido de se ensinar e aprender a língua portuguesa em um contexto no qual os indivíduos já são falantes do idioma. À luz da verdade, o que acontece realmente é o aprimoramento, o desenvolvimento e o aperfeiçoamento da competência da fala e o ensino efetivo da escrita, como forma distinta, porém interligadas, de utilização da língua.

Pensar o ensino de língua portuguesa implica considerarmos o aluno como um ser pensante, que não está apenas esperando passivamente que conhecimentos sejam transferidos e impostos a ele. Nós, professores, lidamos com todo tipo de situação de aprendizagem, variadas culturas, opiniões e ideais, portanto, precisamos estar dispostos a mudar de opinião, a reciclar nossa prática e a buscar conhecimentos.

Os conceitos sobre letramento e multiletramentos abordam pressupostos relativos ao ensino baseado na utilização que se faz do conhecimento adquirido no dia a 
dia e a forma como esse conhecimento é ensinado. A proposta de multiletramentos aqui apresentada foi pensada com o intuito de mostrar aos alunos que a língua se faz presente em situações diversas da vida cotidiana, além do ambiente escolar. Consideramos importante que sejam trabalhadas as competências que envolvem a oralidade e a escrita, para que o aluno possa se comunicar adequadamente em diferentes contextos.

Percebemos, em nossa prática atuante de sala de aula, que a expressividade oral não preenche lugar de destaque nas atividades escolares. A nosso ver, o cenário configura-se como problemático já que as aulas de língua portuguesa deveriam preparar o aluno para aplicar sua autonomia em qualquer situação comunicativa. A presente proposta é uma opção para se trabalhar a oralidade nas aulas além dos outros aspectos da língua já mencionados.

Por fim, a elaboração dessa proposta de ensino foi importante para repensarmos nossa própria prática em sala de aula, bem como os objetivos que pretendemos com atividades diversas. Acreditamos que a reflexão sobre o nosso trabalho como professores de língua materna é imprescindível para acompanhar as transformações sociais que acontecem regularmente à nossa volta e trazê-las para o ambiente escolar, incluindo nossos alunos através da informação.

\section{REFERÊNCIAS}

BALMANT, Ocimara. Cresce exposição de jovens na internet. 2012. Disponível em: $<$ http://www.estadao.com.br/noticias/geral,cresce-exposicao-de-jovens-na-internetimp-,968026>. Acesso em: 20 abr. 2018

BAKHTIN, M. M. (1929). Marxismo e filosofia da linguagem. Trad. Michel Lahud et al. São Paulo: Hucitec, 1999. 9. ed. 196 p.

BRASIL. Ministério da Educação e do Desporto; Secretaria de Educação do Ensino Fundamental. Parâmetros curriculares nacionais: língua portuguesa. vol. 2. Brasília, 1997.

DUDENEY, Gavin; HOCLY, Nicky; PEGRUM, Mark. Letramentos Digitais. São Paulo: Parábola Editorial, 2016, 352 p.

MARCUSCHI, Luiz Antônio. Da fala para a escrita: atividades de retextualização. São Paulo: Cortez, 2008. $9^{\mathrm{a}}$ ed.

MESQUITA, Bruna. $90 \%$ dos jovens brasileiros possuem pelos menos um perfil nas redes sociais. 2015. Disponível em: https://exame.abril.com.br/tecnologia/90-dos- 
jovens-brasileiros-possuem-pelo-menos-um-perfil-proprio-em-rede-social/> . Acesso em: 20 abr. 2018

MORAIS, Artur Gomes. Ortografia: ensinar e aprender. São Paulo: Ática, 2010. 136 p. ROJO, Roxane Helena R. MOURA, Eduardo. (Org.). Multiletramentos na escola. São Paulo: Parábola Editorial, 2012. 264 p.

SOARES, Magda. Letramento: um tema em três gêneros. São Paulo: Autêntica 1999. 